\title{
Prediction of Pinus sylvestris clear-wood properties using NIR spectroscopy and biorthogonal partial least squares regression
}

\author{
Torbjörn A. Lestander, Johan Lindeberg, Daniel Eriksson, and Urban Bergsten
}

\begin{abstract}
Thirteen wood parameters were predicted using near infrared (NIR) spectra in the range 780-2380 nm modelled by biorthogonal partial least squares regression. The analysis of parameters and NIR measurements was done on clearwood samples from the base and midstem of Scots pine (Pinus sylvestris L.) from trees at two sites. Calibrations based on the measured parameters at seven growth rings (cambial age ranging between 6 and 42 years) could be divided into three groups: $(i)$ the best accuracy was found for longitudinal modulus of elasticity $(r>0.9)$ followed by bending, compression, and cell length $(0.8<r<0.9)$; (ii) microfibril angle, longitudinal hardness, proportion of latewood, and creep with correlations in the range of 0.7-0.8; and (iii) tangential hardness, cell diameter, and cell wall thickness with $0.4<r<0.7$. It was also shown that juvenile (cambial age $\leq 20$ years) and mature wood can be classified using NIR techniques.
\end{abstract}

\begin{abstract}
Résumé : La régression bi-orthogonale partielle par les moindres carrés a été utilisée pour modéliser 13 paramètres du bois à l'aide de spectres de transmittance dans les longueurs d'onde allant de 780 à $2380 \mathrm{~nm}$ dans le proche infrarouge (PIR). L'analyse des paramètres et des mesures de transmittance dans le PIR a été réalisée sur des échantillons de bois sain provenant de la base du tronc et de la portion intermédiaire de la cime de tiges de pin sylvestre (Pinus sylvestris L.) récoltées dans deux stations. Les étalonnages basés sur la mesure des paramètres dans sept cernes annuels (âge cambial variant de 6 à 42 ans) pouvaient être divisés en trois groupes: ( $i$ ) la plus grande précision a été obtenue pour le module d'élasticité longitudinal $(r>0,9)$ suivi par la flexion, la compression et la longueur des cellules $(0,8<r<0,9)$, (ii) l'angle des microfibrilles, la dureté longitudinale, la proportion de bois final et le fluage de retour avaient un coefficient de corrélation de $0,7-0,8$ et (iii) la dureté tangentielle, le diamètre des cellules et l'épaisseur des parois cellulaires avaient un coefficient de corrélation variant entre 0,4 et 0,7 . Nous avons aussi montré que l'utilisation de la transmittance dans le PIR permet de distinguer le bois juvénile (âge cambial $\leq 20$ ans) du bois mature.
\end{abstract}

[Traduit par la Rédaction]

\section{Introduction}

Wood is mostly regarded as a raw material without welldefined and -described properties. The utilization and view of wood as an engineering material needs a scientific-based description of wood in, for example, structural, chemical, and mechanical terms, as is done for other materials. Thus, wood could then be included in common material databases, thereby making it possible to choose as an alternative in construction other than that where wood normally is used today. Such a renewed view founded on documented properties ought to widen the assortment of wood products and further develop the forest industry. The rapid progress in

Received 25 May 2007. Accepted 9 February 2008. Published on the NRC Research Press Web site at cjfr.nrc.ca on 24 June 2008.

T.A. Lestander. ${ }^{1}$ Swedish University of Agricultural Sciences, Unit of Biomass Technology and Chemistry, P.O. Box 4097, SE-904 03 Umeå, Sweden.

J. Lindeberg. Gamla vägen 20, SE-692 33 Kumla, Sweden. D. Eriksson. Swedish University of Agricultural Sciences, Vindeln Experimental Forest, SE-922 91 Vindeln, Sweden. U. Bergsten. Swedish University of Agricultural Sciences, Department of Forest Ecology and Management, SE-901 83 Umeå, Sweden.

${ }^{1}$ Corresponding author (e-mail: torbjorn.lestander@btk.slu.se). process analytical technology and data pattern recognition facilitate the implementation of this more advanced view of wood (Bowyer 2000).

Variation in wood properties depends on genetic and environmental interactions during the growth of individual trees. Earlywood and latewood, juvenile and mature wood, as well as sapwood and heartwood in conifers are examples of such properties that result from natural physiologic processes (Hillis 1987; Larson 1994; Gartner 1995; Zobel and Sprague 1998). Most of the variation (e.g., in fibre length, density and chemical composition) is found within trees (Zobel and van Buijtenen 1989). Wood properties vary radially and longitudinally within a tree, and all show variation within each growth ring.

Near infrared (NIR) spectroscopy is of interest as a process analytical technique to characterize wood because it is a fast and nondestructive method and suitable for online measurements. NIR absorbance spectra are the result of overtone vibrations in bonds of structural groups (e.g., O-H, $\mathrm{C}-\mathrm{H}$ and $\mathrm{N}-\mathrm{H}$ ) in polar molecules. An advantage is that NIR radiation penetrates deeper into samples than ultraviolet, visible, or infrared radiation does (Osborne et al. 1993, Burns and Ciurczak 2001). Studies have also shown that NIR spectroscopy can be used to predict moisture content (Thygesen and Lundqvist 2000a, 2000b); cellulose, hemicellulose, and lignin (Shultz and Burns 1990; Wright et al. 1990; Axrup et al. 2000; Hodge and Woodbridge 2004); 
fibre length (Marklund et al. 1999; Hauksson et al. 2001); microfibril angle (MFA) (Schimleck et al. 2001a; Jones et al. 2005); density (Hoffmeyer and Pederson 1995; Schimleck et al. 2001b, 2002); and aggregated mechanical strength properties of wood, such as modulus of elasticity (MOE) and rupture (Gindl et al. 2001; Thumm and Meder 2001; Kelly et al. 2004).

The NIR technique is now applied routinely in food, chemical, and pharmaceutical industries for process control and determination of product quality (Osborne et al. 1993; Burns and Ciurczak 2001). Because of the large amount of overlapping vibrations, interpretation of NIR models is not as straightforward as for the fundamental vibrations found in the infrared spectrum. However, multivariate models are, besides being predictive, also useful in the interpretation. Partial least squares (PLS) regression is often used to obtain calibrations between spectral data and reference variables (Martens and Næs 1989). An obstacle in interpretation of PLS models is that that the commonly used basic PLS algorithms either result in nonorthonormal loading vectors or nonorthogonal score vectors. Therefore, orthogonal factorization of the PLS solutions (Ergon 2002) gives a standardized platform for interpretation independent of applied PLS algorithms (Lestander and Geladi 2005; Lestander and Rhén 2005). The result of biorthogonal partial least squares (BPLS) regression has orthonormal loading vectors and orthogonal score vectors as in principal component analysis (PCA).

Based on the fact that NIR reflectance spectra of wood contain information on structural or physical and chemical properties, one objective was to use NIR data modelled by BPLS to predict variation of properties describing structure in wood and mechanical parameters and to interpret results. Another objective was to investigate if juvenile and mature wood could be classified by NIR spectroscopy. The overall objective was to study the possibilities to characterize wood, especially complex parameters like modulus of elasticity, by NIR spectroscopy online analysis in sawmills or later in the wood-refining process to determine wood properties in real time.

\section{Materials and methods}

\section{Wood samples and determination of wood properties}

Scots pine (Pinus sylvestris L.) was used as a model species in this study. Wood samples were collected from eight $(4 \times 2)$ representative trees in two stands $\left(64^{\circ} 09^{\prime} \mathrm{N}\right.$, $\left.19^{\circ} 40^{\prime} \mathrm{E}\right)$ in northern Sweden. The stands were subjected to different silvicultural regimes, and more details are given by Eriksson (2005). Stem disc sections in each tree were taken from stump height and midstem between two branch whorls 20 and 30 internodes up in the trees of the 56- and 85-year-old stands, respectively. Clear-wood samples for testing mechanical properties, representing specific cambial ages (ring number from pith) of $6,11,15,20,26,33$, and 42 years, were taken from the stem sections according to Fig. 1. The two highest and two lowest cambial ages were selected to maximize the age intervals and the number of samples in the top and base, respectively, for the two stands. In the interval from 11 to 26 years, the cambial age of 20 years was chosen because this cambial age by rule of thumb
Fig. 1. Sampling of clear wood in Scots pine stem discs and corresponding coordinate system in radial (R), tangential (T), and longitudinal (L) direction perpendicular to each other. Wood sections A and $\mathrm{B}$ and stem disc $\mathrm{C}$ show positions for taking subsamples for different measurements (see text).

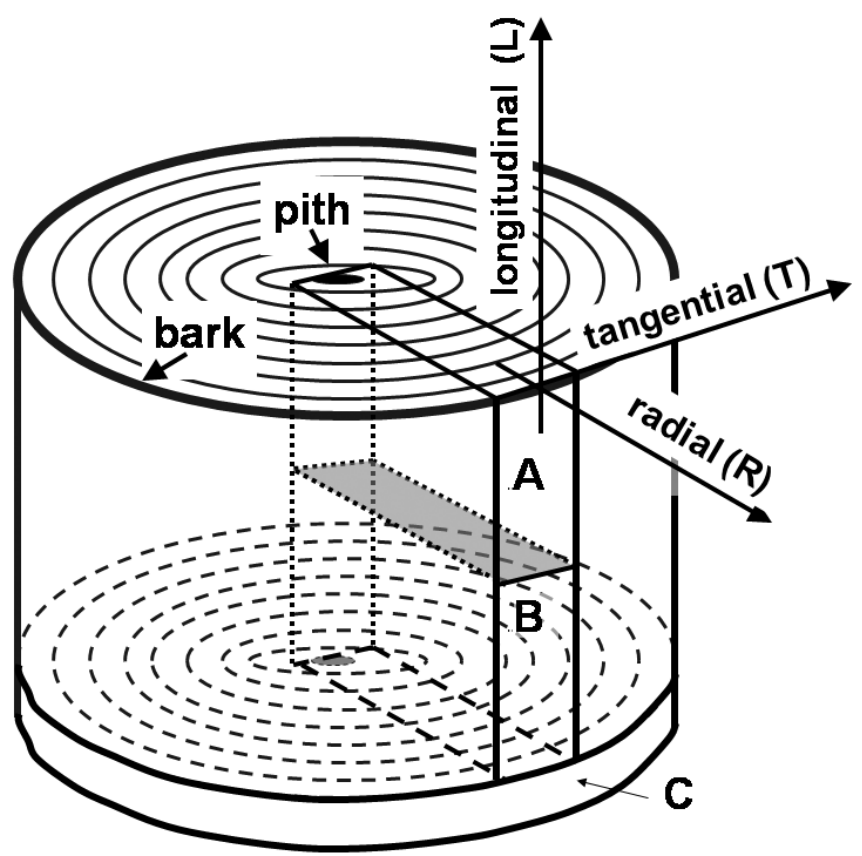

is often set to be the limit between juvenile and mature wood of Scots pine in boreal forests. Samples to test MOE and bending strength were taken from the same disc and were taken at position A from one side, whereas samples to test creep of MOE were taken from the adjacent side in the tangential direction. Samples for compression strength and Brinell hardness in the tangential direction were taken at position $\mathrm{B}$ and from either side. Stem discs from position $\mathrm{C}$ were taken for measurements of Brinell hardness in the longitudinal direction. Samples representing cambial age of 6 years were missing from stump height, and samples representing cambial age of 42 years were missing from midstem for one of the stands, so that the total number of analysed samples was 100. Samples for measurements using NIR spectroscopy and to determine reference values for structural characteristics were taken from the samples to test creep of MOE. The samples scanned by NIR had radial, tangential, and longitudinal dimensions of 1.7-17.9 mm, 50.6$75.2 \mathrm{~mm}$, and 19-21 mm, respectively (Fig. 1).

The following reference variables were determined for the target growth rings using clear-wood samples (see text above, Table 1, and Fig. 1):

1. Proportion of latewood according to Mork's (1928) definition measured on $20 \mu \mathrm{m}$ thick sections in the radial $\times$ tangential plane by using a light microscope.

2. Tracheid length (mean measured length-weighted contour length), mean tracheid width, and mean cell wall thickness (CWT) within targeted cambial ages were analysed using a Kajaani FiberLab 3.5 optical fiber dimension analyzer (Metso Automation Inc., AB, Solna, Sweden).

3. MFA in the S2 layer of 20 and 10 iodide-stained trach- 


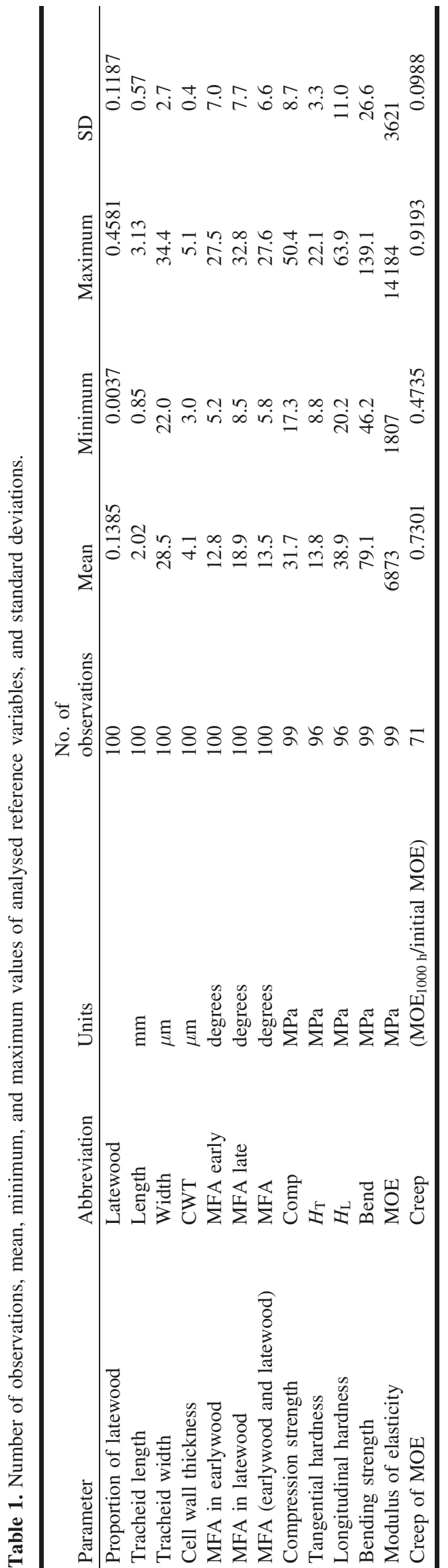

eids from earlywood and latewood, respectively, measured by using a light microscope. The method is described in Eriksson (2005). Overall mean MFA for each target growth ring was calculated from the means of earlywood and latewood and the measured proportion of latewood.

4. Compression strength in the longitudinal direction determined according to the European standard EN 408 (CEN 2003) on samples with radial dimension, $r$, tangential dimension, $t$, and longitudinal dimension, $l$, where $r$ is the width of three successive growth rings with the target growth ring in the middle and $r=t$ if $r \leq 6.3 \mathrm{~mm}$ otherwise $t=6.3 \mathrm{~mm}, l=6 t$.

5. Brinell hardness in tangential $\left(H_{\mathrm{T}}\right)$ and longitudinal $\left(H_{\mathrm{L}}\right)$ direction analysed according to Holmberg (2000) by applying a load of $490.5 \mathrm{~N}$ on a steel sphere that was $10 \mathrm{~mm}$ in diameter. The load was applied for $15 \mathrm{~s}$, held constant for $30 \mathrm{~s}$, and released for $15 \mathrm{~s}$. Samples were $20 \mathrm{~mm}$ long in the tested direction.

6. MOE, bending strength, and creep of MOE in longitudinal direction was analysed according to the European standard EN 408 (CEN 2003) by a four-point bending test on samples that were three growth rings wide with tangential and longitudinal dimensions of $6.3 \mathrm{~mm}$ and $120.5 \mathrm{~mm}$, respectively. This kind of four-point test exposes the sample to compression and to tensile that is orthogonal to the applied force on the opposite side of the sample. Creep of MOE is the decrease of MOE over time and is expressed here as MOE at $1000 \mathrm{~h}$ relative to initial MOE. The load to determinate creep of MOE was ca $20 \%$ of the maximum stress and the duration of this test was $1000 \mathrm{~h}$.

Samples used to analyse the mechanical properties were conditioned at $20{ }^{\circ} \mathrm{C}$ and $65 \%$ air humidity before measurements. The analysis of compression strength, MOE, bending strength, and Brinell hardness was conducted using a Hounsfield 5000 Universal Testing Instrument. Creep was determined in an apparatus using hanging weights. Further information regarding analysed reference variable measurement is given by Eriksson (2005).

The A samples (Fig. 1) that were selected to be scanned by NIR were embedded at $60{ }^{\circ} \mathrm{C}$ for $1 \mathrm{~h}$ with a mixture of equal amounts of camphor $\left(\mathrm{C}_{10} \mathrm{H}_{16} \mathrm{O}\right)$ and naphthalene $\left(\mathrm{C}_{10} \mathrm{H}_{8}\right)$ having $\mathrm{C}=\mathrm{O}$ and $\mathrm{C}=\mathrm{C}$ double bonds besides $\mathrm{C}-\mathrm{H}$ bonds. These substances were premixed and heated at $40{ }^{\circ} \mathrm{C}$ and this mixture was used to improve the ability to cut sections for determining latewood proportion. The aim of this treatment was also to conserve the wood prior to NIR measurement and future nondestructive analyses. Schimleck et al. (2003) removed extractives in wood samples by extracting them during $18 \mathrm{~h}$ with warm acetone $\left(\mathrm{C}_{3} \mathrm{H}_{6} \mathrm{O}\right)$ containing $\mathrm{C}=\mathrm{O}$ double bonds and $\mathrm{C}-\mathrm{H}$ bonds.

\section{NIR spectroscopy}

A NIR spectrometer (Foss NIRSystems 6500, Höganäs, Sweden) with a fibre-optic probe was used to collect spectral data. The wood samples were placed on a thin glass slide (1.0 $\mathrm{mm}$ distance to the sample) covering the measurement probe and centred over the measurement area of the probe that was $4 \mathrm{~mm}$ in diameter. Because the width of the target rings varied, overlapping spectral information from 
the nearest neighbouring rings was sometimes included in the collected spectra. The NIR measurements were conducted in the radial direction $(\mathrm{R})$ on the plane perpendicular to the longitudinal direction (L) with the surface in RTplane illustrated in Fig. 1 by a shaded plane at the bottom of sample A. Mean spectra of 32 scans were collected for each sample around the target growth rings. The reflectance spectra $(\boldsymbol{r})$ were recorded at room temperature (ca. $20{ }^{\circ} \mathrm{C}$ ) between 780 and $2380 \mathrm{~nm}$ (801 wavelengths) with spectral resolution of $2 \mathrm{~nm}$ and transformed into absorbance values (x) using $\boldsymbol{x}=\log \left(\boldsymbol{r}^{-1}\right)$, where $\boldsymbol{x}$ and $\boldsymbol{r}$ are vectors of values. The collected NIR spectra were ordered in a matrix $(\mathbf{X})$ of dimension $N \times K$ with each row of the $N$ spectra in the matrix constituting absorbance values of $K$ wavelengths: from the first row $\left[\begin{array}{lllll}x_{11} & x_{12} & x_{13} & \ldots & x_{1 K}\end{array}\right]$ to the $N$ th and last row $\left[\begin{array}{llll}x_{N 1} & x_{N 2} & x_{N 3} \ldots x_{N K}\end{array}\right]$ with $K$ columns. Each of the corresponding reference variables was ordered in column vectors $(\boldsymbol{y})$ containing the $N$ observed values (scalars) of the actual reference variable $\left[\begin{array}{llll}y_{1} & y_{2} & y_{3} \ldots y_{N}\end{array}\right]^{\mathrm{T}}$ (the column vector is written here as a transposed row vector of scalar values) with the dimension $N \times 1$.

\section{Modelling}

The overlapping and wide peaks of overtone vibration in the NIR wavelength interval give highly collinear neighbouring wavelengths. Solutions based on ordinary least squares (OLS) regression, also called multiple linear regression, will in such cases give poorly defined solutions. Therefore, multivariate methods, such as principal component regression but preferably PLS regression (Wold et al. 1983; Martens and Næs 1989) that maximize covariance, have to be used to obtain unique solutions. This is also valid when the number of variables is greater than the number of observations as in this study.

The prediction using BPLS regression is exactly the same as PLS prediction provided that the same number of model components is used. One advantage is that BPLS gives orthonormal loadings and orthogonal scores in the interpretation of the solution. For mean-centred data, the BPLS model for the calibration set is

$$
[1] \quad \boldsymbol{y}=\mathbf{X} \boldsymbol{b}_{\mathrm{BPLS}}+\boldsymbol{f}
$$

where $\boldsymbol{y}$ is a vector having dimension $N \times 1$ and containing values of the response variable, $\mathbf{X}$ is the spectral matrix $(N \times K)$ consisting of $\mathrm{N}$ calibration objects and $\mathrm{K}$ wavelengths, $\boldsymbol{b}$ is a vector $(K \times 1)$ of the BPLS regression coefficients, and the vector $f(N \times 1)$ contains the residual values.

The BPLS regression results in values of the $\boldsymbol{b}_{\mathrm{BPLS}}$ regression coefficients (see eq. 4) such that the predicted values $\left(y_{\mathrm{p}}\right)$ of the reference variable can be calculated in this case by using centred NIR spectra from other wood samples. If the values of the reference variable are also known $\left(\boldsymbol{y}_{\mathrm{t}}\right)$, a residual vector $\left(\boldsymbol{f}_{\mathrm{t}}\right)$ can be calculated. For data centred to the calibration set, predictions using test sets are calculated as

$$
\text { [2] } \quad \boldsymbol{y}_{\mathrm{p}}=\boldsymbol{y}_{\mathrm{t}}+\boldsymbol{f}_{\mathrm{t}}=\mathbf{X}_{\mathrm{t}} \boldsymbol{b}_{\mathrm{BPLS}}
$$

Here, the vector $\boldsymbol{y}_{\mathrm{p}}$ with dimension $J \times 1$ contains the predicted values, the vectors $\boldsymbol{y}_{\mathrm{t}}$ and $\boldsymbol{f}_{\mathrm{t}}(J \times 1)$ consist of known reference values and the residuals $\left(\boldsymbol{f}_{\mathrm{t}}=\boldsymbol{y}_{\mathrm{p}}-\boldsymbol{y}_{\mathrm{t}}\right)$, respectively. The matrix $\mathbf{X}_{\mathrm{t}}(J \times K)$ constituting a test set for validation, is built up with $J$ measured and centred spectra of $K$ wavelengths. The vector $\boldsymbol{b}_{\mathrm{BPLS}}$ contains the coefficients calculated according to eq. 4 below.

BPLS factorization according to Ergon (2002) uses singular value decomposition to orthogonalize the PLS solution. Here, the factorization is done by the way of the orthogonalized PLS algorithm (Martens and Næs 1989), and therefore, the decomposition is based on the product of the orthogonalized score vectors in the $\mathbf{T}$ matrix, of the non-normalized loading vectors in the transposed $\mathbf{P}$ matrix, and of the PLS weights in the $\mathbf{W}$ matrix and is written as follows:

$$
\begin{aligned}
\text { [3] } \mathbf{X}=\left(\mathbf{T P}^{\mathrm{T}} \mathbf{W}\right) \mathbf{W}^{\mathrm{T}}+\mathbf{E}=\left(\mathbf{U S} \mathbf{V}^{\mathrm{T}}\right) \mathbf{W}^{\mathrm{T}}+\mathbf{E} & \\
& =\mathbf{T}_{\mathrm{b}} \mathbf{V}_{\mathrm{b}}^{\mathrm{T}}+\mathbf{E}
\end{aligned}
$$

where $\mathbf{T}$ with dimension $N \times A$ is the matrix of orthogonal score vectors, $A$ is the number of model components, the superscript $\mathrm{T}$ denotes a transposed matrix, $\mathbf{P}(K \times A)$ and $\mathbf{W}(K \times A)$ are the matrices of loading and weight vectors, respectively, calculated according to the orthogonalized PLS algorithm and $\mathbf{E}$ is the residual matrix $(N \times K)$. Further, $\mathbf{U}$ $(N \times A)$ is the orthogonal matrix of eigenvectors fulfilling $\mathbf{U}^{\mathrm{T}} \mathbf{U}=\mathbf{I}$, where $\mathbf{I}$ is the identity matrix, $\mathbf{S}(A \times A)$ is the diagonal matrix constituting the square roots of the eigenvalues of $\mathbf{T}$ (the diagonal elements are singular values and the off-diagonal elements are zero), $\mathbf{V}(A \times A)$ is the orthogonal matrix of eigenvectors fulfilling $\mathbf{V}^{\mathrm{T}} \mathbf{V}=\mathbf{I}$, the orthogonalized score matrix $\mathbf{T}_{\mathrm{b}}(N \times A)$ is calculated from US and finally, the matrix of orthonormalized loading vectors $\mathbf{V}_{\mathrm{b}}(K \times A)$ is calculated from $\mathbf{V}^{\mathrm{T}} \mathbf{W}^{\mathrm{T}}$.

The score vectors $\left(\boldsymbol{t}_{\mathrm{b}}\right)$ of the $\mathbf{T}_{\mathrm{b}}$ matrix and the loading vectors $\left(v_{\mathrm{b}}\right)$ of the $\mathbf{V}_{\mathrm{b}}$ matrix are different than those of the PLS solution, and the components may have reversed order. The nonorthogonalized PLS algorithm can also be factorized into a BPLS solution (Ergon 2002; Lestander 2003).

The BPLS regression coefficients are calculated as

$$
\text { [4] } \quad \boldsymbol{b}_{\mathrm{BPLS}}=\mathbf{V}_{\mathrm{b}}\left(\mathbf{T}_{\mathrm{b}}^{\mathrm{T}} \mathbf{T}_{\mathrm{b}}\right)^{-1} \mathbf{T}_{\mathrm{b}}^{\mathrm{T}} \boldsymbol{y}=\mathbf{V}_{\mathrm{b}} \boldsymbol{q}_{\mathrm{BPLS}}
$$

In loading plots, variables in the same direction as the $\boldsymbol{q}$ vector $\left(\boldsymbol{q}_{\mathrm{BPLS}}=\left(\mathbf{T}_{\mathrm{b}}^{\mathrm{T}} \mathbf{T}_{\mathrm{b}}\right)^{-1} \mathbf{T}_{\mathrm{b}}^{\mathrm{T}} \boldsymbol{y}\right)$ are positively or negatively related to the response variable $\boldsymbol{y}$.

Mathematical pretreatments of NIR spectra may remove information of physical properties of the measured wood samples, e.g., particle size and particle shape of irregular surfaces. There are also scattering phenomena, such as Mie scattering on the microscopic scale and Rayleigh scattering on the molecular scale (Born and Wolf 1999), that may be influenced by pretreatments. Therefore, the only pretreating of spectral data done prior to BPLS modelling was mean centring.

\section{Test sets}

One problem in using test sets on relatively small data sets is that global modelling often has to be applied-all observations excluding outliers are used for calibration modelling and for validation that by rule of thumb often consist of about one-seventh of the observations. If observations belonging to the outer shell of the model space are included 
in the validation set, prediction error will increase because of the low density of observations in the neighbouring model space. In large sets of observations, local models of observations surrounding the observations that are going to be predicted can be used.

In this study, we used two types of validation. The first was based on leaving one observation out in each remodelled and centred calibration set. This reflects cross validation, but it can be argued that it also reflects a real situation where a new observation is predicted. The leave one out modelling is here denoted L1O. In all, up to 100 calibration runs using L1O modelling were done for each wood parameter. The second type was based on distances to the global model centre using PCA for the NIR spectra alone. The Euclidian distance to the centre of the PCA model was calculated for each spectral observation, and the observations were reorganized in order of increasing distance. A window consisting of every seventh ordered observation was created and used as a test set in the first round of validation. The following six rounds of validation used test sets that were moved downstream one position for each validation round and after seven validations 98 of the 100 observations had been used as test sets. This modelling of evenly distributed observations in the test set is here called ED7 modelling. It should be noted that these types of test sets were not independent and the studied wood samples were not ideal for obtaining independent and external test sets. However, the methods used gave guidance in selection of the number of components.

\section{Number of components}

The number of model components was based on the first local minimum of the prediction error calculated as the root mean square error of prediction (RMSEP; see following section). The second local minimum was sometimes used if the first local minimum was of high value and found in the first or second component. In both the L1O and the ED7 modelling the mean value of the RMSEPs in the different validation rounds were used to find local minima in prediction error.

\section{Model diagnostics and software}

The validation diagnostics were based on the vector of residuals $\left(\boldsymbol{f}_{\mathrm{t}}\right)$ according to eq. 2 and the different multivariate models were evaluated using several diagnostics according to Table 2 .

RMSEP and bias have the same unit as the reference variable. The $Q^{2}$ gives the amount of explained variation and is dimensionless as is the ratio of performance to deviation (RPD), which reflects the predicative ability of the calibration. RPD values based on independent test sets and in the range of 1.5-2.5 indicate that calibrations can be used for coarse screening purposes (Schimleck et al. 2003). Values $>2.5$ are satisfactory for screening, whereas models with RPD values $>10$ have excellent performance (Williams and Sobering 1993). The L1O and ED7 approach to obtain test sets implied several PLS models and diagnostic values given below are mean values.

All PLS remodelling was done in Matlab (The Mathworks, Inc., Natick, Mass.) and PLS_Toolbox (Eigenvector Research, Manson, Wash.; Wise et al. 2003). PCA model- ling and the use of jack-knifing (Westad and Martens 2000) to find significant $(p \leq 0.05)$ regression coefficients were based on SIMCA version 10.0 (Umetrics AB, Umea, Sweden). Global PLS models done in SIMCA were transformed using code published by Lestander (2003) into BPLS models.

\section{Interpretation of models}

Interpretation was based on BPLS models and significant PLS regression coefficients for the different wood parameters. All data were included in these models using the number of model components that minimized RMSEP according to the L1O approach. Interpretation was focused on strength parameters and the two first components with the highest degree of explained variation.

\section{Results and discussion}

\section{Overview of studied wood parameters}

The wood parameters, except for MFA of earlywood and latewood, were modelled by PCA. Figure 2 shows the calculated loading and score values that explained $70 \%$ of the variation. In the resulting three significant components, the parameters MFA and $H_{\mathrm{T}}$ showed no grouping or close association to each other or other parameters. The tracheid dimensions width and CWT formed one group as well as the mechanical property parameters MOE, bending, and compression, which were grouped together with proportion of latewood. The $H_{\mathrm{L}}$ was associated with the later group. Tracheid length and creep showed close association with each other.

The first PCA component explained $63 \%$ of the variation in reference parameters and separated MFA from the mechanical property parameters (MOE, bending, and compression; Fig. 2). It also divided the data set according to the two sites indicating that the main difference between the stands was found in MFA and grouped strength parameters, but also that MFA was negatively correlated with strength. The second component was associated with longitudinal differences between upper and lower locations in the trees and spanned between hardness on one side and tracheid dimensions and creep on the other side.

\section{Modelling}

The 13 studied wood parameters were based on RPD divided into three groups with different correlations to the modelled NIR spectra; see Tables 3 and 4 where the results of validation are presented. The highest correlation $(Q=0.91)$ was found for MOE followed by bending strength $(0.84<$ $Q<0.88)$, cell length $(0.77<Q<0.82)$ and compression strength $(0.83<Q<0.86)$. The second group included MFA with a correlation of about 0.8 with variation in the range of $0.76-0.84, H_{\mathrm{L}}(0.70<Q<0.75)$, creep $(0.71<Q$ $<0.74)$, and proportion of latewood $(0.78<Q<0.81)$. The third group (lowest RPDs) included CWT $(0.47<Q$ $<0.63)$, cell diameter $(0.49<Q<0.58)$, and $H_{\mathrm{T}}(0.56<Q$ $<0.66)$.

There was a clear tendency in the modeling that increased variation width within a reference variable, defined as the ratio of maximum and minimum for the reference variables, resulted in models with higher prediction accuracy (data not 
Table 2. Diagnostics used for evaluation of calibration models.

\begin{tabular}{ll}
\hline Diagnostic & Calculation* \\
\hline Root mean square error of prediction (RMSEP) & RMSEP $=\left[\boldsymbol{f}_{\mathrm{t}}^{\mathrm{T}} \boldsymbol{f}_{\mathrm{t}} J^{-1}\right]^{1 / 2}$ \\
Coefficient of multiple determination $\left(Q^{2}\right)$ & $Q^{2}=1-\boldsymbol{f}_{\mathrm{t}}^{\mathrm{T}} \boldsymbol{f}_{\mathrm{t}}\left(\boldsymbol{y}_{\mathrm{t}}^{\mathrm{T}} \boldsymbol{y}_{\mathrm{t}}\right)^{-1}$ \\
Bias & $\operatorname{Bias}=\mathbf{1}^{\mathrm{T}} \boldsymbol{f}_{\mathrm{t}} J^{-1}$ \\
Ratio of performance to deviation (RPD) & $\mathrm{RPD}=\left[\left(\boldsymbol{y}_{\mathrm{c}}^{\mathrm{T}} \boldsymbol{y}_{\mathrm{c}}\right)(I-1)^{-1}\left[\boldsymbol{f}_{\mathrm{t}}^{\mathrm{T}} \boldsymbol{f}_{\mathrm{t}}(J-1)^{-1} J^{-1}\right]^{-1}\right]^{1 / 2}$
\end{tabular}

*I, number of observations the calibration set; $J$, number of observations the test set.

Fig. 2. Biplot of the first two loading (+) and score (first site: solid triangles, base; open triangles, top; 2nd site: solid circles, base; open circles, top) components of a PCA model explaining $70 \%$ of the variation. The percentages of explained variation are given within parenthesis. Bend, bending strength; Comp, compression strength; CWT, cell wall thickness; $H_{\mathrm{L}}$ and $H_{\mathrm{T}}$, Brinell hardness in longitudinal and tangential direction, respectively; MFA, microfibril angle; Length, cell length; Width, cell width.

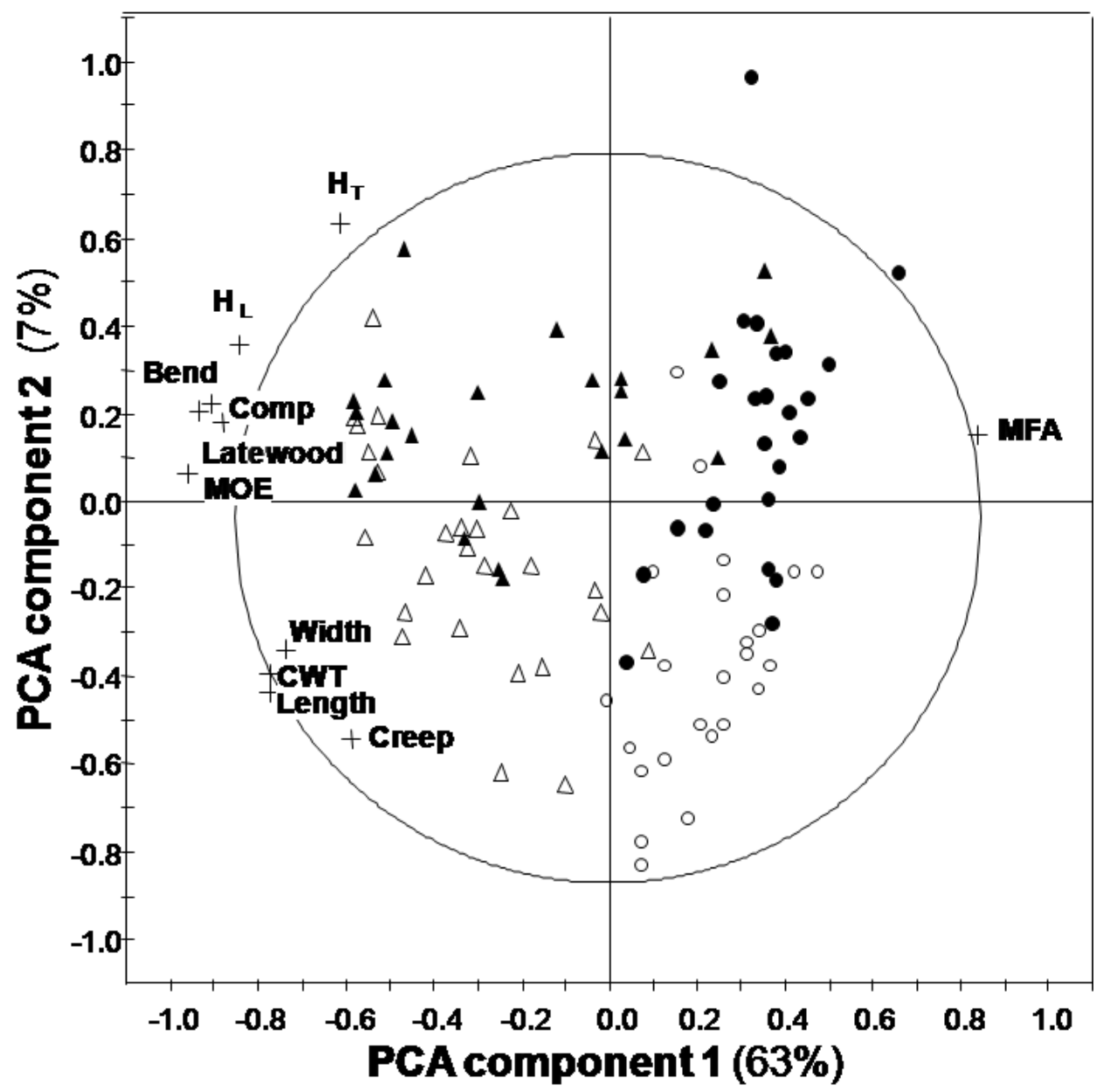

shown). Normalization of reference variables in the modeling did not affect this tendency.

The results for some wood parameters (e.g., MFA) showed predictions of somewhat lower accuracy than would be expected based on other published data. The embedding of samples and the thin glass in between sample introduce variability in the spectral data. The constant circular measurement area of the probe introduces additional variance if targeted ring widths were less than the measurement diameter; in such cases, neighbouring rings contributed to the collected spectra. Also, varying sample dimensions that, in some cases, were less than the measurement diameter intro- duced spectral variation. In this study, the values of the reference variables were analysed from wood subsamples other than those used to collect NIR data (see Fig. 1). All this introduced variation and sampling errors that lowered calibration accuracy. The analysis explained $58.1 \%-69.8 \%$ of the variation in MFA. In this study, MFA was measured on 20 and 10 tracheids in earlywood and latewood, respectively, using a light microscope. These numbers of tracheids may be too small to obtain representative means of the whole tracheid population of a whole ring. Other studies showing NIR calibrations with higher accuracy for MFA used X-ray spectroscopy to determine MFA values (e.g., 
Table 3. Mean values of L1O modelling to predict wood parameters.

\begin{tabular}{lrrclcl}
\hline Parameter & No.* & \multicolumn{1}{c}{$A$} & RMSEP & $Q^{2}$ & Bias & RPD \\
\hline MOE & 99 & 10 & 1457.2 & 0.822 & 678.5 & 3.19 \\
Bend & 99 & 10 & 11.63 & 0.712 & 2.54 & 2.95 \\
Tracheid length & 100 & 8 & 0.282 & 0.597 & -0.1451 & 2.92 \\
Creep & 71 & 5 & 0.0428 & 0.553 & 0.0093 & 2.88 \\
Comp & 99 & 8 & 4.87 & 0.686 & 1.94 & 2.66 \\
MFA & 100 & 8 & 3.65 & 0.677 & 0.82 & 2.58 \\
MFA earlywood & 100 & 8 & 3.86 & 0.698 & 0.64 & 2.58 \\
MFA latewood & 100 & 8 & 4.49 & 0.620 & 0.05 & 2.50 \\
$H_{\mathrm{L}}$ & 96 & 6 & 6.72 & 0.559 & 1.06 & 2.46 \\
Latewood & 100 & 8 & 0.0872 & 0.603 & 0.0199 & 2.15 \\
$H_{\mathrm{T}}$ & 96 & 1 & 2.87 & 0.440 & 0.83 & 2.04 \\
Tracheid width & 100 & 6 & 2.68 & 0.241 & 0.55 & 1.89 \\
CWT & 100 & 7 & 0.41 & 0.220 & 0.07 & 1.88 \\
\hline
\end{tabular}

Note: See Table 1 for definitions of parameters. Variables are as follows: $A$, number of model components; RMSEP, root mean square error of prediction; $Q^{2}$, coefficient of multiple determination; RPD, ratio of performance to deviation.

*Number of test set observations equal to number of PLS models.

Table 4. Mean values of seven rounds of ED7 modelling to predict wood parameters.

\begin{tabular}{llrllll}
\hline Parameter & $\begin{array}{l}\text { Mean no. of } \\
\text { observations }\end{array}$ & \multicolumn{1}{c}{$A$} & RMSEP & $Q^{2}$ & Bias & RPD \\
\hline MOE & 13.9 & 10 & 1476.80 & 0.830 & -24.32 & 3.18 \\
Bend & 13.9 & 9 & 12.30 & 0.778 & 0.22 & 2.91 \\
Comp & 13.9 & 10 & 4.34 & 0.739 & -0.18 & 2.87 \\
Tracheid length & 14.0 & 6 & 0.3015 & 0.674 & -0.0078 & 2.72 \\
MFA latewood & 14.0 & 8 & 4.30 & 0.652 & 0.13 & 2.64 \\
MFA earlywood & 14.0 & 8 & 4.28 & 0.585 & 0.12 & 2.57 \\
MFA & 14.0 & 8 & 4.04 & 0.581 & 0.11 & 2.55 \\
Late wood & 13.3 & 8 & 0.0689 & 0.652 & -0.0016 & 2.53 \\
CWT & 14.0 & 8 & 0.3061 & 0.403 & 0.0015 & 2.40 \\
$H_{\mathrm{L}}$ & 13.4 & 3 & 7.79 & 0.485 & 0.06 & 2.30 \\
Creep & 9.9 & 5 & 0.0626 & 0.510 & -0.0006 & 2.27 \\
Tracheid width & 14.0 & 8 & 2.15 & 0.334 & 0.02 & 2.24 \\
$H_{\mathrm{T}}$ & 13.4 & 1 & 2.62 & 0.336 & 0.02 & 2.24 \\
\hline
\end{tabular}

Note: See Table 1 for definitions of parameters. Mean number of observations was calculated from the seven test sets.

Evans 1999), i.e., calibrations between two different spectroscopic methods (e.g., Schimleck et al. 2003); in some cases, the calibrations were also based on the same subsample.

\section{Interpretation of models}

The different validations (L1O and ED7) gave the number of components to minimize prediction error. Global BPLS models using all observations and mean number (integer) of components were calculated to produce data for interpretation.

In Fig. 3, which is an example of two orthogonal loading vectors explaining $46.7 \%$ of the variation in MOE, it is shown that the fit to the $\boldsymbol{q}_{\mathrm{BPLS}}$ loading direction was related to the two trend lines with loading vector $\boldsymbol{v}_{b_{1}}$ or $\boldsymbol{v}_{b_{2}}$ as independent variable in a first-order polynomial fitted to the data. Further, it seems from the wavelengths with significant coefficients (large solid circles) that they were associated to the two trends: the $\boldsymbol{f}\left(\boldsymbol{v}_{b_{1}}\right)$ and the $\boldsymbol{f}\left(\boldsymbol{v}_{b_{2}}\right)$ trend to wavelengths $>1990 \mathrm{~nm}$ and $<1990 \mathrm{~nm}$, respectively.
Wavelengths with significant $\boldsymbol{b}_{\mathrm{BPLS}}$ coefficients were for the whole MOE model located in 9 regions and 12 single wavelengths at 780-820 (N-H), 1040-1098 (N-H, C-H, C$\mathrm{C}$, close to the detector shift at $1100 \mathrm{~nm}$ ), 1200-1226 (C$\mathrm{H}), \quad 1360-1374 \quad(\mathrm{C}-\mathrm{H}), \quad 1432-1440 \quad(\mathrm{~N}-\mathrm{H}, \mathrm{O}-\mathrm{H}, \mathrm{C}-\mathrm{H})$, 1774-1796 (C-H, O-H), 1904-1912 (O-H), 1970, 1978, 2118-2128, 2152, 2220, 2226-2232, 2236, 2240, 2316, $2322(\mathrm{C}-\mathrm{H}), 2354,2358,2368$, and $2376 \mathrm{~nm}$. The chemical assignments within parenthesis are according to lists published by Osborne et al. (1993) and Shenk et al. (2001).

The overtone bands in NIR spectra overlap making interpretation more difficult. This was further complicated by the conserving medium that contained double bonds of $\mathrm{C}=\mathrm{O}$ and $\mathrm{C}=\mathrm{C}$ besides $\mathrm{C}-\mathrm{H}$ bonds. According to the significant wavelengths (Fig. 3) the MOE parameter involved $\mathrm{C}-\mathrm{H}, \mathrm{O}-\mathrm{H}$, and $\mathrm{C}-\mathrm{C}$ in combination with $\mathrm{C}-\mathrm{H}$ vibrations, as well as $\mathrm{N}-\mathrm{H}$ vibrations. None of the significant wavelengths in the MOE model were targeted to the double bond $\mathrm{C}=\mathrm{C}$ as observed for bending or $\mathrm{C}=\mathrm{O}$ as in compression strength and 
Fig. 3. Plot showing the two first loading vectors of a BPLS model with 10 components and MOE as reference variable. The large solid circles are wavelengths with significant $b_{\mathrm{BPLS}}$ coefficients, the shaded arrow shows the $\boldsymbol{q}_{\mathrm{BPLS}}$-loading direction, and the shaded lines are the two trends of the loading data: $f\left(\boldsymbol{v}_{b_{1}}\right)$ with lower slope than $\boldsymbol{f}\left(\boldsymbol{v}_{b_{2}}\right)$.

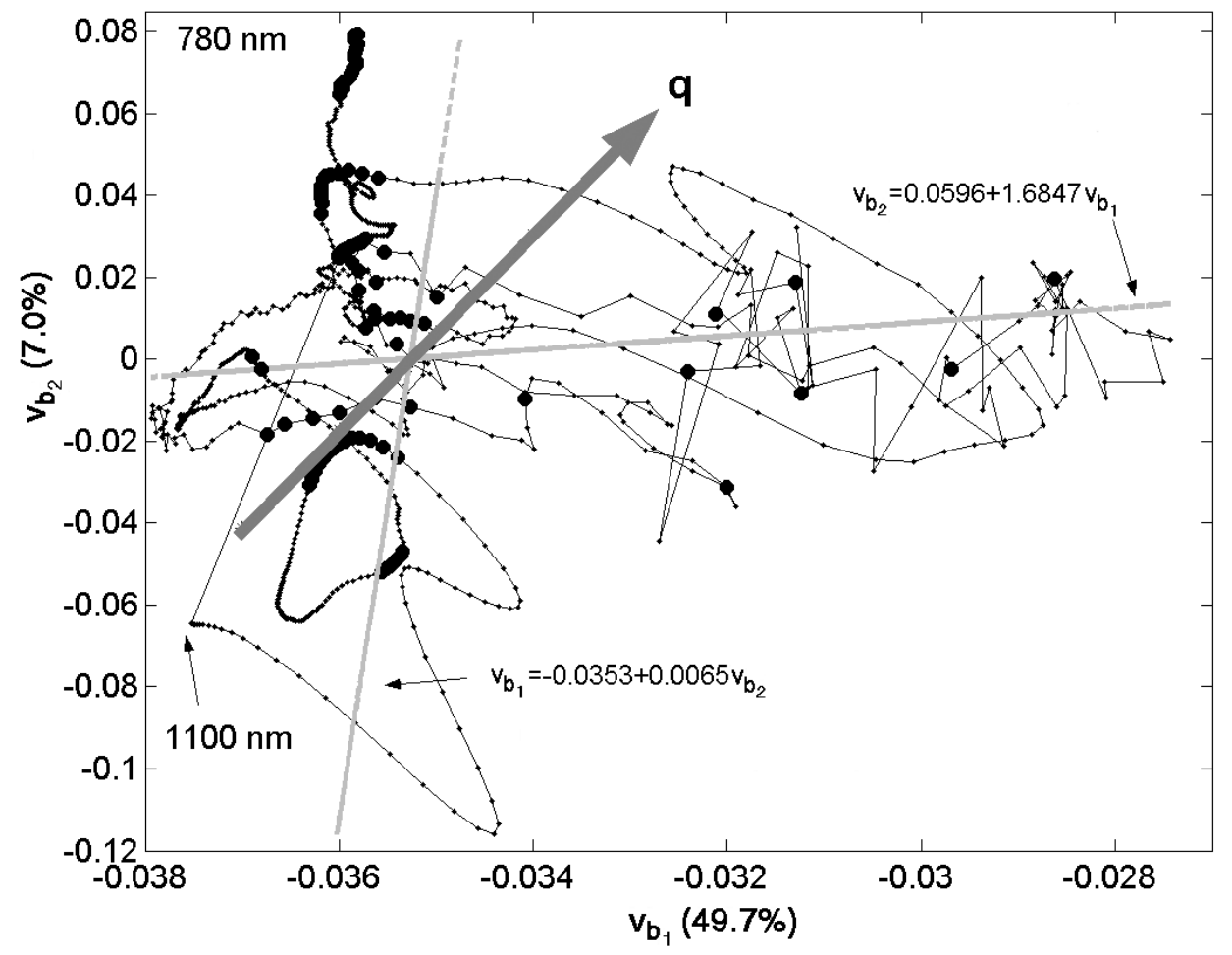

creeping. Compression strength also showed influence from the $\mathrm{S}-\mathrm{H}$ band. Creep and in particular tracheid length were influenced by $\mathrm{N}-\mathrm{H}$ overtones.

Concerning structural parameters, tracheid length and MFA showed higher correlations to NIR spectra than CWT and tracheid width did. The NIR spectra were collected from the RT plane in which tracheids with their fibre bundles were cut. This RT surface then contained a distribution that consisted of more or less random cross sections of cut tracheids, i.e., sampling along the variation in longitudinal direction of the tracheids with tapering ends. We speculate that this may be the reason why the parameters tracheid width and CWT had low correlations with the NIR spectra.

The projection of the orientation of microfibril bundles in the RT plane is dependent on the cross-section angle. Higher angles present a larger surface of the microfibril bundles in the RT plane provided that the tracheid orientation is orthogonal to the RT plane. We hypothesize that, besides chemical explanations, this may be a cause to the higher explained variation $(58.1 \%-69.8 \%)$ for MFA than for CWT and tracheid width.

The two NIR models explained $59.7 \%$ and $67.4 \%$ of the varitation in tracheid length. It may be possible that the NIR radiation interfered with lumen width and depth in cut tracheids and with surface boundaries between tracheids and, thus, penetrated deeper the longer the tracheid length was. If such phenomena occurred, then absorbance patterns related to mean penetration depth ought to correlate with mean tracheid length.

Creep (51.0\%-55.3\% of variation explained) was associated with tracheid length according to the PCA model.
The mechanical property parameters MOE, bending, and compression showed the highest correlations, with $68.6 \%$ $83.0 \%$ explained variation. The four-point test of these parameters includes both compression and tensile strength in the longitudinal direction orthogonal to the applied force. These tests also affected a larger wood volume than that of the hardness test using a steel sphere. Only 33.6\%-44.0\% of the variation in $H_{\mathrm{T}}$, the only strength parameter tested in that direction, was explained, whereas $48.5 \%-55.9 \%$ was explained in the longitudinal direction $\left(\mathrm{H}_{\mathrm{L}}\right)$.

\section{Juvenile versus mature wood}

Figure 4 presents the predicted class values obtained by ED7 modelling of the two classes: juvenile wood, in this case classified as cambial age $\leq 20$ years, and mature wood, with cambial age more than 20 years.

Of the 100 predicted values, two at cambial age 15 years, four at 20 years, and five at 26 years were falsely classified according to the limit set at 0.5 . The L1O modelling gave a higher rate $(26 \%)$ of falsely classified observations. As expected, most of them (62\%) were in transitional wood (cambial rings 15-26) because of the gradual change from "pure" juvenile to "pure" mature wood shown by the fitted polynomial in Fig. 4. This change was also the case when cambial age was used as the response variable in L1O modelling, which explained $47.3 \%$ of the spectral variation (data not shown). A gradual decrease in fibril angle but increase in fibre length, width, and CWT when going from juvenile to mature wood has been reported in many studies (Atmer and Thörnqvist 1982; Mencuccini et al. 1997; Mattsson 2002). 
Fig. 4. Plot of predicted class value and growth ring from pith based on PLS modelling of class juvenile wood (solid circles; cambial age $\leq 20$ years) and mature wood (open circles; cambial age $>20$ years). The broken horizontal line at class value 0.5 marks the limit between the two classes.

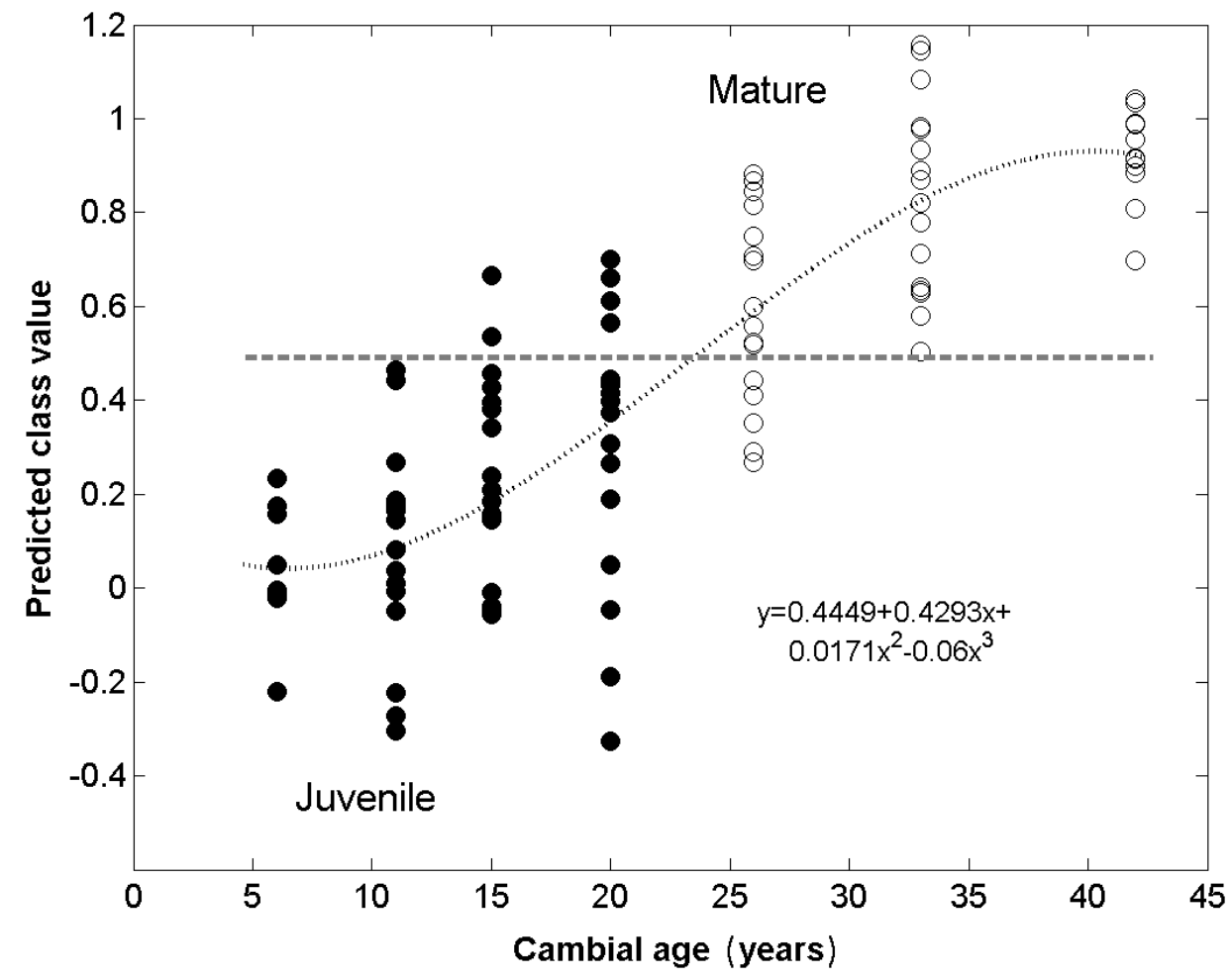

Microfibrils in the S2 layer of the cell walls in wood, the thickest layer constituting ca. 90\% of the fibre mass (Batchelor et al. 2000), mainly control wood dimension stability. In Nordic conifers, juvenile wood of the 10-20 innermost growth rings has, when compared with mature wood, increased longitudinal shrinking and swelling but decreased tangential and radial shrinking and swelling. This can cause economic loss if boards are warped and askew because of heterogeneity in MFA. Therefore, documented information of proportions of juvenile wood in single sawn boards is of great need to avoid problems concerning warping and dimension stability of wood.

The result showed that it is possible to use NIR spectroscopy to distinguish between cambial ages of wood samples. Our results support the finding by Via et al. (2005) who could separate juvenile from mature wood in longleaf pine (Pinus palustris Mill.) with some overlap using principal component regression based on NIR spectra within 1000$2500 \mathrm{~nm}$. However, age alone is not a good predictor of the wood characteristics connected to juvenility and maturity, respectively, and the classification made here was mainly a split of the samples into two halves. Still, these findings open up the possibilities for online classifications and measurements of proportion of juvenile wood in sawn products.

It has also been shown that heartwood formation in Scots pine that produces pinosylvine is possible to correlate to NIR spectra obtained by FT-Raman spectroscopy (Bergström 2003) and that the zone of intermediate wood of sapwood and heartwood was only a few millimetres in the radial direction. Because also structural (e.g., lignification of ray parenchyma cells) and other chemical changes occur in pine heartwood, we postulate that NIR can be used to separate these wood classes, perhaps even with lower rate of false classifications than for juvenile and mature wood.

\section{Conclusion}

The results illustrated that it is possible to use NIR data modelled using biorthogonal partial least squares and predict variation of properties describing structure in wood and mechanical parameters in clear-wood samples of Scots pine. The general conclusion was that NIR offers good possibilities to characterize wood, especially complex parameters like modulus of elasticity. The results are of importance in the endeavour toward documented wood properties as well as better control of wood dimension stability.

The results support the possibilities to use online analysis in sawmills or later in the wood-refining process to determine wood properties in real time. Thereby, it may be possible to deliver quantities of different wood qualities with guaranteed minimum values on a specific list of parameters according to the norm used for other materials by engineers.

\section{Acknowledgements}

The authors express their sincere gratitude to the Kempe Foundations and the Swedish University of Agricultural Sciences for financial support.

\section{References}

Atmer, B., and Thörnqvist, T. 1982. Fiberegenskaper i gran (Picea abies Karst.) och tall (Pinus sylvestris L.). [Fibre properties in Norway spruce and Scots pine.] Department of Wood Science, Swedish University of Agricultural Sciences, Uppsala, Sweden. 
Axrup, L., Markides, K., and Nilsson, T. 2000. Using miniature diode array NIR spectrometers for analysing wood chips and bark samples in motion. J. Chemom. 14: 561-572. doi:10.1002/ 1099-128X(200009/12)14:5/6<561::AID-CEM608>3.0.CO;2-2.

Batchelor, W.J., Conn, A.B., and Parker, I.H. 2000. Comparison of techniques to measure the fibril angle. Appita J. 53: 432-437.

Bergström, B. 2003. Chemical and structural changes during heartwood formation in Pinus sylvestris. Forestry (Oxford), 76: 45-53.

Born, M., and Wolf, E. 1999. Principles of optics: electromagnetic theory of propagation, interference and diffraction of light. 7th ed. Cambridge University Press, Cambridge, U.K.

Bowyer, J.L. 2000. Wood science in a changing world-where are we headed? Wood Sci. Technol. 34: 175-181. doi:10.1007/s00 2260000049.

Burns, D., and Ciurczak, E.W. 2001. Handbook of near-infrared analysis. 2nd ed. Marcel Dekker, New York.

Comité Européen de Normalisation (CEN). 2003. Timber structures-structural timber and glued laminated timberdetermination of some physical and mechanical properties. CEN, Brussels. 89/106/EEC, CEN/TC 124, EN 408:2003.

Ergon, R. 2002. PLS score-loading correspondence and bi-orthogonal factorization. J. Chemom. 16: 368-373. doi:10.1002/cem.736.

Eriksson, D. 2005. Scots pine wood: an anatomical structure in the tree and an engineering material in industry. Licentiate dissertation. Swedish University of Agricultural Sciences, Department of Siviculture, Umeå, Sweden. Rep. No. 65.

Evans, R. 1999. A variance approach to the X-ray diffractometric estimation of micofibril angle in wood. Appita J. 52: 283-289.

Gartner, B.L. 1995. Plant stems, physiology and functional morphology. Academic Press, New York.

Gindl, W., Teischinger, A., Schwanninger, M., and Hinterstoisser, B. 2001. The relationship between near infrared spectra of radial wood surfaces and wood mechanical properties. J. Near Infrared Spectrosc. 9: 255-261.

Hauksson, J.B., Bergqvist, G., Bergsten, U., Sjöström, M., and Edlund, U. 2001. Prediction of basic wood properties for Norway spruce. Interpretation of near infrared spectroscopy data using partial least squares regression. Wood Sci. Technol. 35: 475-485. doi:10.1007/s00226-001-0123-3.

Hillis, W.E. 1987. Heartwood and tree exudates. Springer-Verlag, Berlin.

Hodge, G.R., and Woodbridge, W.C. 2004. Use of near infrared spectroscopy to predict lignin content in tropical and sub-tropical pines. J. Near Infrared Spectrosc. 12: 381-390.

Hoffmeyer, P., and Pederson, J. 1995. Evaluation of density and strength of Norway spruce wood by near infrared reflectance spectroscopy. Holz. Roh. Werkst. 53: 165-170. doi:10.1007/ BF02716418.

Holmberg, H. 2000. Influence of grain angle on Brinell hardness of Scots pine (Pinus sylvestris L.). Holz. Roh. Werkst. 58: 91-95. doi:10.1007/s001070050392.

Jones, P.D., Schimleck, L.R., Peter, G.F., Daniels, R.F., and Clark, A. 2005. Nondestructive estimation of Pinus taeda L. wood properties for samples from a wide range of sites in Georgia. Can. J. For. Res. 35: 85-92. doi:10.1139/x04-160.

Kelly, S.S., Rials, T.G., Snell, R., Groom, L.H., and Sluiter, A. 2004. Use of near infrared spectroscopy to measure the chemical and mechanical properties of solid wood. Wood Sci. Technol. 38: $257-276$.

Larson, P.R. 1994. The vascular cambium: development and structure. Springer-Verlag, Berlin.

Lestander, T.A. 2003. Multivariate NIR studies of seed-water interaction in Scots pine seeds (Pinus sylvestris L.). Swedish
University of Agricultural Sciences, Umeå, Sweden. Sylvestria 282.

Lestander, T.A., and Geladi, P. 2005. NIR spectral information to predict water content of pine seeds from multivariate calibration. Can. J. For. Res. 35: 1139-1148. doi:10.1139/x05-046.

Lestander, T.A., and Rhén, C. 2005. Multivariate NIR spectroscopy models for moisture, ash and calorific content in biofuels using bi-orthogonal partial least squares regression. Analyst, 130: 1182-1189. doi:10.1039/b500103j. PMID:16021218.

Marklund, A., Paper, M., Hauksson, J.B., and Sjöström, M. 1999. Prediction of strength parameters for softwood kraft pulps. Multivariate data analysis based on orthogonal signal correction and near infrared spectroscopy. Nord. Pulp Pap. Res. J. 14: $140-148$.

Martens, H., and Næs, T. 1989. Multivariate calibration. John Wiley \& Sons Ltd., Chichester, UK.

Mattsson, S. 2002. Effects of site preparation on stem growth and clear wood properties in boreal Pinus sylvestris and Pinus contorta. Department of Silviculture, Swedish University of Agricultural Sciences, Umeå, Sweden.

Mencuccini, M., Grace, J., and Fioravanti, M. 1997. Biomechanical and hydraulic determinants of tree structure in Scots pine: anatomical characteristics. Tree Physiol. 17: 105-113. PMID:14 759880.

Mork, E. 1928. Die Qualität des Fichtenholzes unter besonderer Rücksichtnahme auf Schleifund Papierholz. Papierfabrikant, 26: 741-747.

Osborne, B.G., Fearn, T., and Hindle, P.H. 1993. Practical NIR spectroscopy with applications in food and beverage analysis. 2nd ed. Longman Scientific \& Technical, Harlow, UK.

Schimleck, L.R., Evans, R., and Ilic, J. 2001a. Estimation of Eucalyptus delegatensis wood properties by near infrared spectroscopy. Can. J. For. Res. 31: 1671-1675. doi:10.1139/ cjfr-31-10-1671.

Schimleck, L., Evans, R., and Ilic, J. 2001b. Application of near infrared spectroscopy to a diverse range of species demonstrating wide density and stiffness variation. IAWA J. 22: 415-429.

Schimleck, L.R., Evans, R., and Matheson, A.C. 2002. Estimation of Pinus radiata D. Don clear wood properties by near-infrared spectroscopy. J. Wood Sci. 48: 132-137. doi:10.1007/BF00 767290.

Schimleck, L.R., Stürzenbecher, R., Mora, C., Jones, P.D., and Daniels, R.F. 2003. Comparison of Pinus taeda L. wood property calibrations based on NIR spectra from the radial-longitudinal and radial transverse faces of wooden strips. Holzforschung, 59: 214-218.

Shenk, J.S., Workman, J.J., and Weterhaus, M.O. 2001. Application of NIR spectroscopy to agricultural products. In Handbook of near-infrared analysis. Edited by D. Burns and E.W. Ciurczak. 2nd ed. Marcel Dekker, New York. pp. 419-474.

Shultz, T.P., and Burns, D.A. 1990. Rapid secondary analysis of lignocellulose: comparison of near infrared (NIR) and fourier transform infrared (FTIR). TAPPI J. 73: 209-212.

Thumm, A., and Meder, R. 2001. Stiffness prediction of radiata pine clearwood test pieces using near infrared spectroscopy. J. Near Infrared Spectrosc. 9: 117-122.

Thygesen, L.G., and Lundqvist, S.O. 2000a. NIR measurement of moisture content in wood under unstable temperature conditions. Part 1. Thermal effects in near infrared spectra of wood. J. Near Infrared Spectrosc. 8: 183-189.

Thygesen, L.G., and Lundqvist, S.O. 2000b. NIR measurement of moisture content in wood under unstable temperature conditions. Part 2. Handling temperature fluctuations. J. Near Infrared Spectrosc. 8: 191-199. 
Via, B.K., Shupe, T.F., Stine, M., So, C.L., and Groom, L.H. 2005. Tracheid length prediction in Pinus palustris by means of near infrared spectroscopy: the influence of age. Holz. Roh. Werkst, 63: 231-236. doi:10.1007/s00107-004-0567-x.

Westad, F., and Martens, H. 2000. Variable selection in near infrared spectroscopy based on significance testing in partial least squares regression. J. Near Infrared Spectrosc. 8: 117-124.

Williams, P.C., and Sobering, D.C. 1993. Comparison of commercial near infrared transmittance and reflectance instruments for analysis of whole grains and seeds. J. Near Infrared Spectrosc. 1: 25-32.

Wise, B.M., Gallagher, N.B., Bro, R., and Shaver, J.M. 2003. PLS_Toolbox, version 3.0 edition. Eigenvector Research Inc., Manson, Wash.
Wold, S., Martens, H., and Wold, H. 1983. The multivariate calibration problem in chemistry solved by the PLS method. In Proceedings of the Conference on Matrix Pencils, 22-24 March 1982, Umeå, Sweden. Edited by A. Ruhe and B. Kågström. Lecture Notes in Mathematics. Springer-Verlag, Heidelberg. pp. 286-293.

Wright, J.A., Birkett, M.D., and Gambino, M.J.T. 1990. Prediction of pulp yield and cellulose content from wood samples using near-infrared reflectance spectroscopy. TAPPI J. 73: 164-166.

Zobel, B.J., and Sprague, J.R. 1998. Juvenile wood in forest trees. Springer-Verlag, Berlin.

Zobel, B.J., and van Buijtenen, J.P. 1989. Wood variation: its cause and control. Springer-Verlag, Berlin. 